\title{
SOME PROBLEMS IN THE MEDICAL PREPARATION OF FORCES FOR SERVICE OVERSEAS*
}

\author{
Major-General D. G. LEVIS, O.B.E., B.A., M.B., M.R.C.S., L.R.C.P., D.P.H. \\ Director of Army Health
}

The Army Strategic Command has the task of training, preparing and providing forces for service outside the United Kingdom. There will be occasions when these forces are required at extremely short notice.

The troops of Strategic Command may be required to reinforce and operate with an existing overseas garrison, or as long as Dependent Territories continue to exist, to operate in an independent role in support of their governments. On other occasions it is conceivable that they may be required as the United Kingdom contribution to a Commonwealth or Allied Force which is formed to meet some particular purpose. Examples of each of these from the past are: the reinforcement of Malaysia, the short notice despatch of troops to Bermuda to meet an internal security situation and the contribution made to the United Nations Forces in Cyprus.

Each month, from the troops within Strategic Command, a battalion with essential supporting elements is nominated for "Spearhead " duties and is accordingly prepared for movement to any part of the world. The leading elements are at twenty-four hours notice to emplane with the follow-up group at seventy-two hours notice. There is also the potential for further build up should this be necessary. Spearhead troops therefore must clearly be prepared in every way for deployment in any direction. They must be prepared for wide differences of climate, to operate in desert or jungle, in mountains or plains, in swamp or savannah, in highly developed countries or in primitive circumstances, or in various combinations of these topographical circumstances.

This includes medical preparation. This, as we all know (or should know), goes far beyond the provision of medical personnel, and resources for the collection, treatment and care of casualties, along with an assortment of prophylactic vaccinations. The wider aspects of the medical preparation of troops for overseas, perhaps because they are not essentially clinical in content, tend to be overlooked, not only by medical officers, but also by those who may be responsible for the planning of the operation. Over the years, in order to help to achieve the necessary standard of preparation, the Army Medical Services have formulated the doctrine of "Prevision and Provision". This doctrine is clearly defined in Army Medical Directorate Bulletin No. 21. This Bulletin, which is an individual issue to all medical officers, is by no means as widely studied and familiar as it should be. The principles it lays down will never date and will always have a universal application. Certain of the techniques of preventive preparation which these principles imply are, of course, liable to modification as further scientific knowledge becomes available and as military technology advances. My colleagues in this presentation will touch upon some of the physiological and psychological implications consequent upon the moves of human beings between widely differing climates and geographies in high speed sophisticated aircraft. Some of these may call for modification of preparative techniques and of our ideas of the medical care of troops in transit and after their arrival at their destination. It is not my intention today to give a formalised

*As presented at the Director-General of Army Medical Services Exercise, October, 1968. 
rehash of A.M.D. Bulletin No. 21. Instead, for a few minutes, I would like to deal with one particular aspect of it-" the Health Appreciation "-which is likely to present us with problems in the future.

The problems will arise because of the radical changes which are occurring in the Army. These changes are not restricted to size, organisation and equipments, but also include its strategic role. Within the foreseeable future the Army could be almost entirely based in the United Kingdom and the European Continent. Its first priority is to underline an essentially European strategy. The opportunities for operational incursions in an independent role into countries outside Europe could vanish completely. Service outside the European context would be restricted to possible contributions to a Commonwealth or Allied Force. Consequent upon this our military medical thinking could become essentially European in content, and there exists the danger that we might lose touch with those skills and techniques essential for the preparation and total medical care of troops operating outside a European context. This fading of our expertise could be reflected in restriction of our previsionary thinking and in the preparation of our health appreciations should such operations be suddenly forced upon us.

This hypothesis is not so fanciful as it would appear. Indeed it can find support in our history. In 1854 the British Army had had no serious overseas adventures since Waterloo in 1815. I discount the Afghan wars and other similar adventures of the British Establishment in India because it is a matter of history that those with Indian experience were mistrusted by the Horse Guards who virtually ignored the Indian Establishment. The Army that went to the Crimea was essentially the product of a European-minded and European-orientated Staff. You will recall that even its Commander-in-Chief habitually referred to the enemy as "The French". The military medical expertise of the Indian Establishment, even when allowance is made for the then state of scientific knowledge, if it had been applied to the Crimean Army, could have prepared it to meet the cholera at Varna and the effects of heat it encountered on the approach march to the Alma, while Indian Frontier experience could have helped mitigate the effects of the cold it encountered before Sebastopol. Medical expertise, based on rich experience, was not used. The health appreciation, if indeed one was made at all, was probably irrelevant and provision was totally lacking. The result we know only too well. We also know where the blame was laid.

Our first problem of the future therefore is likely to be a scarcity of medical officers with the necessary medical experience of overseas who will be able to make realistic and practicable health appreciations for military operations in countries outside the European scene. It could be argued that the instruction given to medical officers both at the Royal Army Medical College and the Army School of Health will prevent the development of such a problem. But theoretical knowledge is not enough, however well it may be taught. Indeed without the knowledge of the geographical background against which such teaching is to be practised some distorsion of emphasis in the health appreciation is inevitable and with this distorsion of emphasis will come the impracticability of its recommendations. In support of this view I can again call on history. Here is an extract from the campaign diary maintained by Field Marshal Sir Garnet Wolseley during the expedition to relieve Khartoum in 1884. On December 19th of that year he wrote: "There is nothing like personal experience no matter how slight to give you an idea of a country; a little of it is worth all the information to be obtained in the Library of the Geographical Society .....". 
At that particular time the gallant Field Marshal was being justifiably irritated by the amount of theoretical advice he was receiving as to what he should or should not do to further his military objective. His personal experience of the country revealed its impracticalities. It is agreed that the situation is not yet acute since we still possess a number of overseas stations outside Europe in which it is possible for medical officers to gain experience. But I would strike a note of warning in respect of these. Service in a military hospital in Singapore or Hong Kong is not the entire answer. Medical officers of all clinical skills should endeavour to serve outside such settings, and alongside troops in the more remote places in such Commands. They should assess the problems that face the civilian medical administration against the total medical care thought necessary for the soldier. The more remote and rural the setting the more valuable it will be. In these two particular theatres the progress and development of civilian health services may convey the impression that the introduction of troops into such places at some future dates on an operational basis will present few problems in their medical preparation. In less well developed areas an entirely different position will present itself.

Exclusively European experience and theoretical instruction will not prepare medical officers of the future to meet the problem of prevision or to make their health appreciation for troops destined for operations outside a European context. The fullest use must be made of the opportunities given by overseas exercises. Medical representation on preliminary reconnaissances must always be pressed for; it should not be the senior officers who go, but the younger and middle-piece officers who will be those who are to provide and guide our Service in the future. The Staff argument that, if a medical officer goes on such reconnaissances, then ORD and REME and so on will demand representation, it not entirely valid. If trouble comes it is human recovery and not vehicle recovery that raises the problems.

Exercising units should always take their medical officer who should be required, on his return, to produce a health appreciation. Even if the whole unit does not go the Regimental Medical Officer should still accompany the element that does, even at the expense of the medical cover of the balance remaining in the United Kingdom. It is only in this way that theoretical teaching can be made more meaningful and related in a practical way to possible future military adventures in far-off places, and in which we can build up a cadre of medical officers whose health appreciations will be of real value to their commanders.

The essential combat skills for extra-European operations are being kept alive in the combat troops by overseas exercises. But we, who are responsible for initiating, recommending and possibly teaching the techniques and skills for safe and healthy living under such conditions have only restricted opportunities to train our medical officers who will be responsible for such activities in the future. Here, therefore, is the emergence of a new problem that will face us in preparing troops for overseas-the growing shortage of medical officers who are able to make a worthwhile and practical health appreciation to meet such deployment. Sir Garnet's cri di coeur in 1884 is echoing back at us 84 years later.

The other problem that faces us in our task of preparing troops for world-wide deployment was also defined by this same officer, again in his story of the Khartoum Relief Expedition when he wrote: " . . . it is always so before every fresh campaign; 
one is told hundreds of lies about the country and its inhabitants, and a certain set of croakers never tire of predicting all sorts of evils and misfortunes. The mosquitoes are said to be as large as wasps, every snake deadly and yards long; climate pestiferous, water undrinkable, etc ...."

It is clear from this entry that Sir Garnet had been given a heavy dose of prevision by medical officers who were not only lacking in essential first hand knowledge and experience, but also had no up-to-date and reliable medical intelligence upon which to base their health appreciation and recommendations. There is therefore also the problem of obtaining such intelligence when we are faced with an overseas move to a relatively unfamiliar country.

Modern communications, press, radio and television, World Health Organization information, scientific publications and government reports are sources of information which were unknown in Wolseley's day. But these sources have the disadvantage of distortion, over or under-emphasis, delay or suppression in circulation and in the case of those countries with a low doctor-to-population ratio poor reporting and statistical procedures. Medical Intelligence Summaries tend to be little better than arid catalogues of the diseases stated to be prevalent. If these were to be taken at their face value and our health appreciation based upon them then there is no doubt that we could rightly be included in Wolseley's " certain set of croakers".

We must remember that information contained in these Summaries relates to the indigenous population. Between such a population and a formed body of trained, disciplined and well-nourished troops operating in the particular country there is a wide difference. What may be a major source of morbidity and mortality in a rural and agricultural African or Asian community may have little or no relevance for our troops. On the other hand, conditions with which the indigenous population have learned to live and still apparently function with reasonable efficiency, may well exert a devastating effect upon European troops. Climate and behaviour will be related to military efficiency; military activity itself may upset a natural balance and produce the unexpected, for example, jungle patrolling and leptospirosis - a disease which receives scant mention in most Medical Intelligence Summaries. Personal experience of the country would offset such a shortcoming in our information.

While lack of experience in overseas countries may create difficulty for medical officers in the preparation of worth-while health appreciations from the information contained in Medical Intelligence Summaries, there is the added difficulty which springs from the quality of the information given in these summaries. This is our second problem. As a medical service we must always be endeavouring to improve upon and perfect our system for the garnering of, and keeping up-to-date of medical intelligence, and, at the same time, ensuring its even flow to all concerned.

Of course we do receive Intelligence Staff Medical Summaries about a large number of countries. These in themselves provide excellent base lines from which we can begin our appreciation. But time factors inevitably enter into their production and they cannot always reflect the current health situation. It is our own intelligence system that must fill in the details of this. One is apt to consider that emergent countries have made no public health progress since achieving independence. But is this always true? Some of the conditions in some of our small West Indian Dependencies leave much to be desired. We must appreciate that in many of the newer nations they have large scale schemes for disease eradication operated by outside agencies which are 
being successful in reducing hazards. But, again, a note of warning. Cross reference with World Health Organization reports is essential and we must be clear in our minds of the military significance of, let us say, a malaria eradication campaign which is stated in a Summary to be in the consolidation or maintenance phase. There are plenty of examples of the discovery of foci of transmission in countries said to be in these phases. Even a W.H.O.-certificated eradication cannot be considered a permanent state if adjacent countries are still malarious. The price of eradication is eternal vigilance; this takes money and organization. Apparent success may lead to funds being diverted to other purposes; the organization may run down with the departure of outside expertise; political insecurity will produce the same results. This is but one example of the uncertainty of medical intelligence. Others will doubtless occur to you. Growing urbanization, the replacement of an agricultural subsistence economy by one based on money, civil war and population shifts can upset the epidemiological patterns; development schemes can interfere with the ecologies of both hosts and vectors and changes will occur which cannot be immediately reflected in Medical Intelligence Summaries.

Unless we receive a constant flow of information-not only relevant to patterns of prevalent disease-but of every biological type-we cannot truly assess the hazards to one force or make a worthwhile health appreciation. I should like to give you an example of what I mean. Earlier this year it was proposed to mount a Strategic Command exercise in an African country for an infantry battalion group-indeed it is finishing just about now. The latest available Medical Summary on this country was 5 years old; no check lists had been received. Furthermore, in this interval there had been political upheaval. During the pre-planning negotiations a small group of staff officers visited the country. It was not possible at that time for us to insert a medical officer into this group. Inadvertently the presence of a R.A.M.C. officer in the country with a Joint Services Training Team was overlooked. So, while the Director of Medical Services for the indigenous forces was present at the discussions, we had no direct R.A.M.C. representation. We should not have allowed this to occur. On the return of the group to the United Kingdom, the results of these discussions were circulated. The medical services were asked to immunize the troops who were going on the exercise against trypanosomiasis (one presumed that by this pentamidine prophylaxis was meant); there was mention of "river blindness" (onchocerciasis) and the need for smallpox vaccination. The sum total of the most up-to-date medical intelligence brought back therefore did relatively little to help us to fill in the gaps in our latest Intelligence Summary of medical conditions and help us to depict the current situation. As I have already pointed out, such gaps in these Summaries are largely unavoidable. There was no mention of the falciparum malaria, stated in the Summary to be widespread; no mention of the schistosomiasis stated to be one of the leading causes of human misery and no indication of the potentialities of the reservoirs of yellow fever infection known to exist. It must therefore be presumed that the Director of Army Medical Services (who was also the Civil Director of Medical Services) was giving his views as to how local conditions affected his people. Trypanosomiasis was killing them, onchocerciasis was blinding them, but they were managing to live and work along with malaria and schistosomiasis. In other words there was a local emphasis related to the indigenous population. The Summary mentioned everything, but emphasised malaria and bilharzia. Had trypanosomiasis become a greater menace than either of these in the last 5 years? How seriously should onchocerciasis be taken? The Summary mentioned a Public Health Administ- 
ration and Malaria Control Scheme but, beyond suggesting that mosquito control had slipped back, gave no indication of the efficiency of either. As I have already mentioned, the presence of a R.A.M.C. Officer on the ground was not known to us. Had this officer been briefed on how to prepare a medical intelligence summary, and on the need for regular reporting and the circulation of such information on a systematic basis, we would have been in a better position to prepare our appreciation. It was necessary therefore for us to insert a medical officer in to the main reconnaissance party to bring us right up-to-date rather later in time than was desirable. This, I think, points out one of the ways in which we can improve upon our present system for the collection and collation of medical intelligence. Our representative reported that there was no worth-while public health administration; that anti-malaria schemes were non-existent and even in major centres the risk of falciparum malaria was high; that the medical officer with the J.S.T.T. (this was our first intimation of his presence) was recommending double dosage of prophylactic paludrine; that spraying teams had been trained but there were no insecticides available to them; that schistosomiasis was a serious risk; that pentamidine prophylaxis was unnecessary and onchoceriasis a negligible risk for British troops; that there had been two recent deaths from snake bite of local soldiers in the proposed training area, but that no anti-venom was available in the country; that, apart from fresh meat, fresh items of the type acceptable to British soldiers were limited and the ration would be, in the main, tinned equivalents; that new water supply systems, although installed in the training camps, had yet to be connected up, and in any case the efficacy of chlorination was suspect; that there was a great shortage of medical supplies available for local purchase; that the prestige hospitals showed evidence of maintenance difficulties and that overall the health services were reflecting the universal shortage of foreign currency. Those were some of the extracts from his report. There were a lot more.

So you will appreciate that on the medical intelligence side we were faced with a local distortion of emphasis and an out-of-date Medical Intelligence Summary. Experience had made us suspect the former and to try and improve on the latter before even attempting to prepare our health appreciation. The up-to-date reconnaissance summary enabled us to interpret, advise, plan and provide medical equipment in relation to Facts. Now if we had acted on the out-of-date Summary and on the information brought back by the first planning group we could well have been classified as being amongst Wolseley's "certain set of croakers". Indeed we would have made as much noise as a school of bull frogs.

Medical intelligence about overseas countries is to be acquired in a number of ways. As I have tried to show, the best is the recent personal experience of medical officers who have been trained and briefed in correct reporting, the worst is probably the information brought back by staff officers using an aide-memoire of "A" points which has been compiled by themselves before departure and which is generally restricted to details of the medical attendance, treatment and evacuation facilities, or else to dramatic over-emphasis on the unlikely. As an example I would quote from an Instruction to cover an exercise in France:

“Med. a. Unit M.O.

b. Hospitalization. French Army M.R.S. was in camp.

c. Inoculation and vaccination. D.C.I.(A) 85 of 68 .

d. Emergency evacuation. D.C.I.(A.) 95 of 68.

e. Stores: Viper Serum will be taken." 
I would point out that " Medical" had not been consulted; that there are just as many adders round Longmoor; and the water from a pump in a French farmhouse is probably infinitely more deadly! This is an example of the " every snake deadly and yards long" type of intelligence which so infuriated Wolseley.

The main value of the Medical Intelligence Summaries is that they can provide a base line upon which we can consider our health appreciation. There is however an element of "sameness" about them. This is particularly the case of those summaries of the position in the newly formed African states and other less developed countries. In many there are prestige hospitals but maintenance and supply services may have slipped back. A Public Health Administration may be described in the Summary but be virtually absent. We all know that preventive medicine and sanitary reform programmes tend to receive less financial support than eye-catching curative facilities. Morbidity and mortality statistics are, in general, suspect, particularly in those countries with a low ratio of doctors to the population. Internationally aided schemes for improvement may be losing their impetus for a variety of reasons. None of these are, or can be, reflected in formally circulated Summaries and they can only be brought to light by medical officers who accompany troops on exercises in such countries and who use their eyes and their time to assess and report upon such matters. There is of course a converse to all this, in that unless medical intelligence is up to date, there is no information as to possible improvements that may have taken place. This can result in totally unnecessary prophylactic procedures being imposed upon the troops. We must also remember, when assessing our medical intelligence, that, while the eradication of certain specific conditions may be complete, other conditions previously unrecognised are all too liable to step in and take their places as sources of morbidity and wastage in troops. While malaria may have gone, the increasing urbanization in an African and SouthEast Asian context will create problems of infestation with Aedes and C.p. fatigans with the result that the arboviruses and filariasis become painfully obvious. Medical officers who use their eyes can fill in such details. It should be remembered that once we, in the medical services, state that a particular country is free from malaria, then the logistic planners, ever eager to reduce air-freight loads, will amost certainly say that mosquito nets are unnecessary. With up-to-date intelligence we can correct such thinking and it will be a realistic correction. To make a worth-while health appreciation about any country we need up-to-date intelligence-not mere lists of diseases-the problem is to get it.

So these are the two major problems, as I see them, which we face when preparing a force for overseas. The first is the growing one of building up a body of medical officers with overseas experience outside the European context. This is an essential if the hazards to a military population are to be realistically evaluated and militarily practicable prophylactic procedures imposed.

The second is the need to establish a co-ordinated and systematic scheme for the collection and dissemination of up-to-date medical intelligence about any country in which our troops are liable to serve. This will help to produce the base upon which our health appreciations will be constructed. In other words, they will be realistic and factual and we shall no longer be regarded as "croakers", but rather as valuable advisers.

Both of these problems can be met and overcome by the correct training of our medical officers and I would ask all senior officers to give the matter their attention. 